\title{
Origins of ...
}

\section{Urinalysis in clinical diagnosis}

\author{
J Bolodeoku, D Donaldson
}

It is appropriate to commence this article on the history of urine examination with the words of Auguste Comte (1798-1857), who wrote in Positive Philosophy that "To understand a science it is necessary to know its history". ${ }^{1}$ In this context and with special reference to urine, the most freely accessible of all biological fluids, it is not surprising to know that over the course of history it was probably the first body fluid to be studied scientifically. Indeed, it was Count Antoine Francois de Fourcroy (17551809) who stated in $A$ general system of chemical knowledge, and its application to the phenomena of nature and art, Volume X, Article 25 (translated by W Nicholson), that "The urine of man is one of the animal matters that have been most examined by chemists, and of which the examination has at the same time furnished the most singular discoveries to chemistry, and the most useful application to physiology, as well as the art of healing. This liquid, which commonly inspires men only with contempt and disgust, which is generally ranked amongst vile and repulsive matters, has become, in the hands of the chemists, a source of important discoveries". ${ }^{1}$

One of the earliest references pertaining to the diagnostic value of studying urine is found in the ancient Sanskrit literature. Ants and other insects were observed to accumulate selectively around the sites of urination of certain individuals; this was referred to as "honey urine" or "sugar cane urine", the insects having been attracted to the sweet flavour and meaty smell. The urine had, of course, been passed by people with diabetes mellitus; similar observations had already been reported by ancient Chinese physicians. ${ }^{2}$ Ancient medical texts from Mesopotamia also reveal carefully documented observations on the appearance of urine; there was note; in particular, of the changes in odour and colour. ${ }^{3}$

The earliest procedure described in the literature which could be specifically regarded as a diagnostic test was used, not only to confirm pregnancy, but also to identify the sex of a foetus. These tests were performed about $1000 \mathrm{BC}$ by Egyptian priests who poured urine over mixed cereal seeds. It seems that if germination occurred then the test was regarded as positive; however, it is stated that only by noting the actual type of seed that germinated was it possible to predict the sex of the foetus. ${ }^{2}$ Uroscopy, which was inspection of the urine for diagnostic purposes, had been practised by Hippocrates (460-370 BC); he attempted to link his observations with the doctrine of the four humours-namely phlegm, blood, yellow bile and black bile, which had been proposed earlier by Aristotle (384-322 BC). Aristotle had regarded health as a balance between these four biological components. ${ }^{4}$

In Hippocrates' Book of Prognostics there is a paragraph on uroscopy, in which he described the changes he observed in the composition of urine during the course of fever, both in children and adults; he also included differences in colour and odour. ${ }^{4}$ Inspection of urine in its container was at that time considered to be an effective way of demonstrating, not only fundamental changes in balance of the four humours, but also location of disease within the body; this practise was used for prognostic purposes, too. Uroscopy (which comprised observations on colour, consistency, quantity, transparency, odour, and the presence or absence of froth) was to be part of the diagnostic repertoire for some considerable time and, indeed, was practised by Galen of Pergamum (129 to approx. 199), the Byzantines and the Arabs. Avicenna (980-1037), whose full name was Abu Ali Husain ibn Abdullah ibn Sina, in his vast tome of medical knowledge entitled Canon, developed the art further by taking into consideration the conditions that should be observed prior to collection of a urine sample; he included observations that would enable differentiation of urine samples from other similar liquors that might have been brought with the patient in order to "test the competence of the physician". 5 (Perhaps this was one of the earliest attempts at quality control!)

In the thirteenth century Gilles de Corbeil (?1165-1213), in his analysis of urine inspection, regarded the sample in the urinal as being divisible into four levels, each of which represented the various parts of the body; the uppermost level represented the head, the next the chest, the third the abdomen, and the lowermost level, the urogenital organs. ${ }^{6}$

During the middle ages there was no further progress and uroscopy became the trademark of physicians, even being portrayed in some paintings in which it was not uncommon for a urine glass to represent the sign of a physician (fig 1). This should not, of course, be confused with the uromancers who were popular at that time; they claimed to possess the ability, not only to define disease states by examining the urine, but also to foretell the future. Uromancy was soon to be practised quite widely, being accepted by surgeons, charlatans, apothecaries, 
and physicians; the consequence was to discredit the whole practise of uroscopy, leading later to the derogatory phrase pisseprophet being quite commonly used. ${ }^{5}$ Abuse of the art of uroscopy was reflected in the literature of the time, as is evident from Shakespeare's play, Henry IV, Part II Act I, Scene II, where Falstaff says "Sirra, you giant, what says the doctor to my water?" and to which Page replies "He said, sir, the water itself was a good healthy water; but for the party that owed it, he might have more diseases than he knew for".

Thomas Linacre (1460-1524), founder of the Royal College of Physicians of London and Physician to Kings Henry VII and Henry VIII, was one of the earliest to doubt the diagnostic value of uroscopy (which was ultimately banned by the apothecaries towards the end of the sixteenth century), although he received, not surprisingly, severe opposition from those groups sympathetic to the practise of that art. ${ }^{5}$ It was in the same century that Cardinal Nicolaus Cusanus (1401-1464) suggested that the weighing of urine might be of clinical importance ${ }^{5}$; however, the value of knowing the specific gravity was not to be appreciated for another two centuries and then only after introduction of the urinometer for measuring specific gravity had been made in 1849 by Johann Florian Heller (1813-1871).

In Basel, Switzerland, Philippus Aureolus Theophrastus Bombastus von Hohenheim (1493-1541)-whose name was Latinised to Paracelsus following the acquisition of his medical degree-claimed that there was also much valuable information to be gained from examining urine constituents that were invisible to the naked eye. Accordingly, he proposed the introduction of chemical analysis, thereby introducing the iatrochemical school; this

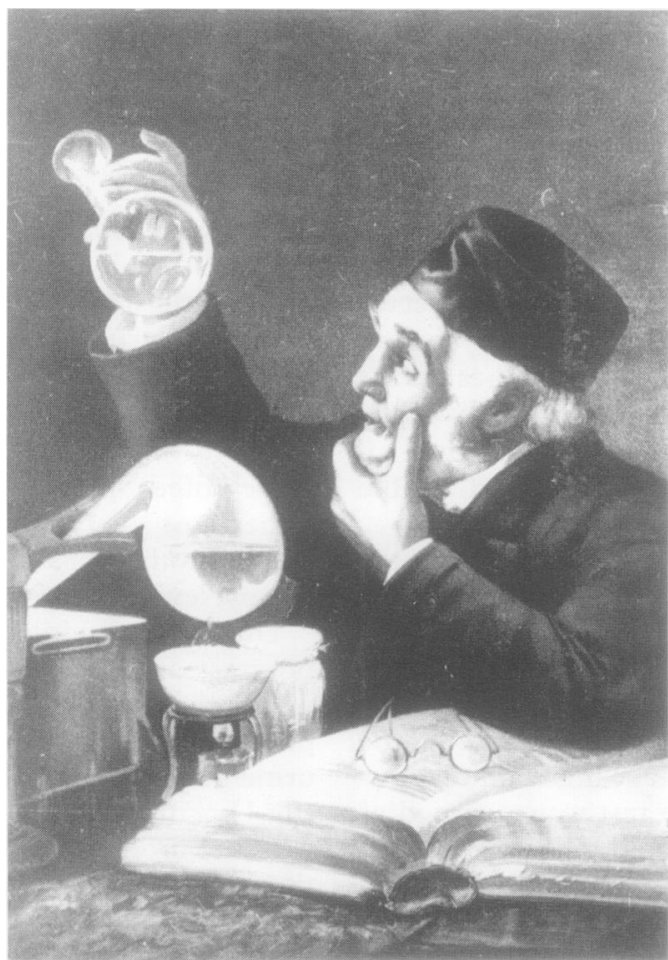

Figure 1 Portrait showing a physician examining a urine specimen with book and chemical apparatus. Courtesy of the Wellcome Institute for the History of Medicine. slowly brought orthodox uroscopy to an end. It was Jan Baptista van Helmont (1577-1644) of Brussels, a contemporary of William Harvey (1578-1657), and one of the unorthodox indi- $c$ viduals of the time, who believed that chemis- $\subseteq$ try would ultimately play an essential role in $\bar{F}$ the diagnosis of disease. Sir Thomas Willis (1621-1675) was sufficiently perceptive to 으 know that a normal urine sample would not necessarily equate with perfect health and $\stackrel{\vec{F}}{\rightarrow}$ should not, therefore, be used as the only diagnostic tool. He was, moreover, critical of the 흠 doctrine that all bodies comprised a combina- $\frac{\pi}{7}$ tion of particles of spirit, sulphur, salt, water, $\stackrel{\mathbb{2}}{\square}$ and earth; nevertheless, he carried out chemi- क cal analyses on urine and firmly believed that $\overrightarrow{0}$ excess or deficiency of one or more of these $\overrightarrow{\vec{H}}$ particles (or an unstable mixture thereof) $\vec{\omega}$ could explain the mechanism behind some dis- $\frac{7}{0}$ eases. $^{6}$

In 1674 sweetness of the urine of certain patients was noted by Sir Thomas Willis (fig 2), who stated that such urine tasted like $\underset{\omega}{N}$ honey; he attributed this taste to the presence 을 of salts and sulphur. He quoted, in relation to diabetics, "...wherefore the urine of the sick is so wonderfully sweet, or hath an honied taste...". However, little true progress had been $\stackrel{\text { क }}{\rightarrow}$ made as no elements had actually been $\vec{\varphi}$ detected and no chemical compounds identi- $\mathscr{\mathscr { C }}$ fied. Another century was to elapse before Matthew Dobson (?1731-1784) of Liverpool published his famous paper entitled Experiments and Observations on the Urine in Diabetes in 1776 , in which he established by chemical $\stackrel{2}{\square}$ analysis that sugar was the agent responsible $\overrightarrow{\vec{B}}$ for the sweetness. It is of interest that at the end $\frac{0}{3}$ of the seventeenth century Frederick Dekkers (1648-1720) of Leyden is said to have detected proteinuria by a test involving the use of heat 홍 and acetic acid. This had, interestingly, been described in some patients with dropsy in 1765 . by Domenico Cotunnius Cotugno (1736-8 1822 ) and it is possible that it was this to which $₹$ Hippocrates was referring when he stated over 음 2000 years ago "...when bubbles settle on the $>$ surface of urine, they indicate disease of the kidneys and that the complaint will be $\tilde{N}$ protracted". The observation did, as is often the case, antedate by many years any clinical N application.

During the eighteenth century, diagnostic emphasis was changing from the art of $\stackrel{\circ}{\frac{0}{C}}$ uroscopy to that of taking a complete clinical $\stackrel{\oplus}{\oplus}$ history and performing a detailed physical examination - as is evident from the anecdote ${ }_{0}^{\circ}$ of a physician who, when asked to make a diag- $\stackrel{\mathbb{D}}{D}$ nosis from inspecting a bootmaker's urine, $\mathbb{\mathbb { D }}$ responded by filling another urinal with his own urine, facetiously requesting the bootmaker to make him a pair of boots that would $\frac{0}{0}$ fit him. ${ }^{4}$

Two physicians, William Charles Wells (1757-1817) and John Blackall (1771-1860), had also described proteinuria in some patients with dropsy; they were, however, unable to make the connection with renal disease. Indeed, they probably went out of their way to claim there was no connection, despite having documented previously the association be 


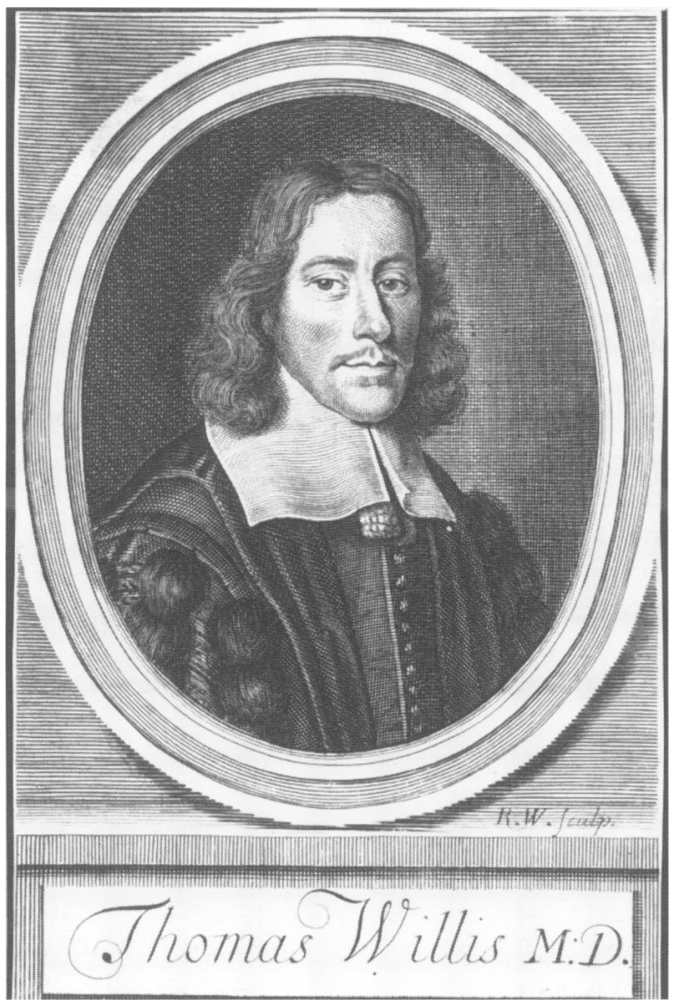

Figure 2 Portrait of Sir Thomas Willis. Courtesy of the Wellcome Institute for the History of Medicine.

tween kidney disease and proteinuria. Richard Bright (1789-1858) at a later date went on to establish that there was a connection between dropsy and proteinuria; this was through his keen powers of observation following his experience of having carried out necropsies on many patients. In 1821 William Prout (17851850) published a book on urine tests, describing in basic terms its general appearance, its reaction to litmus, the measurement of specific gravity, and the precipitation reaction sometimes observed on boiling. Robert Boyle (1627-1691) was the first to demonstrate the presence of sodium chloride in the blood and is said to have suggested that urine might also contain it and consequently should be so tested (fig 3). In the eighteenth century Browne Langrish (d.1759), an enthusiast for the study of experimental medicine, said "...if therefore a bare inspection of urine is of such advantage towards investigating the nature, state, progress and cure of disease: most certainly the natural history of it, or a more curious search into the contents of the urine in every period of the disease will be of moment in discovering the several dyscrasias of the blood, and indicating the cure that we can meet with in the normal way". Browne Langrish documented in his book The Modern Theory and Practise of Physic (London, $1735, \mathrm{p} 51$ ) that physical and chemical analysis of the blood of patients with feverish diseases had been much in vogue, but he anticipated that urine would also be an important product to study further, saying "...the proportions of the several principals of the blood and urine, both in a sound and diseased state, will be highly useful in investigating the causes of the phenomena of diseases". ${ }^{4}$

Following the Renaissance, changes in clinical methods had been taking place as a consequence of the advances in chemistry and physics; these, in turn, had led to the development of specialities such as anatomy, physiology and pathology. Hence, chemistry began to be introduced into the practise of medicine in a more elaborate way. Laurent Lavoisier (1743-1794) had established that respiration was a form of combustion, Richard Bright had demonstrated that albuminuria occurred in renal disease and by the nineteenth century some great advances were being made with the introduction of chemistry into diagnosis. ${ }^{4}$ In 1848 Henry Bence-Jones (1814-1873) was working on the urine with which his name was later to be associated, the same year that Hermann Christian von Fehling (1812-1885) quantitatively determined the presence of reducing substances in some urine samples. Max von Pettenkofer (1818-1901) described the detection of bile salts in urine, and the biuret test for albumin was developed in 1831 by Heinrich Rose. Johann Jacob Bezelius (1779-1848) heralded the discovery of new elements such as cerium, selenium, thorium, and many others; he also observed that normal urine was acidic, had a specific gravity of 1.025 and contained urea, phosphate, sodium chloride, and ammonium chloride. In disease states he also observed that albumin, fibrin, blood, urates, oxalates, xanthine, cystine, sugar, bile, and pus might be present. ${ }^{7}$

Urine testing advanced tremendously during the nineteenth century, as is shown by comparing the initial publication in 1821 by William Prout (1785-1850) with $A$ Guide to Qualitative and Quantitative Analysis of Urine written in 1860 by C Neubauer (1830-1879) and J Vogel (1814-1880) and translated in 1863 by W O Markham; the latter volume contained a list of 17 normal and 17 abnormal constituents, together with a host of quantitative tests for some 20 substances, compared with Prout's tests which only covered protein, acidity, alka

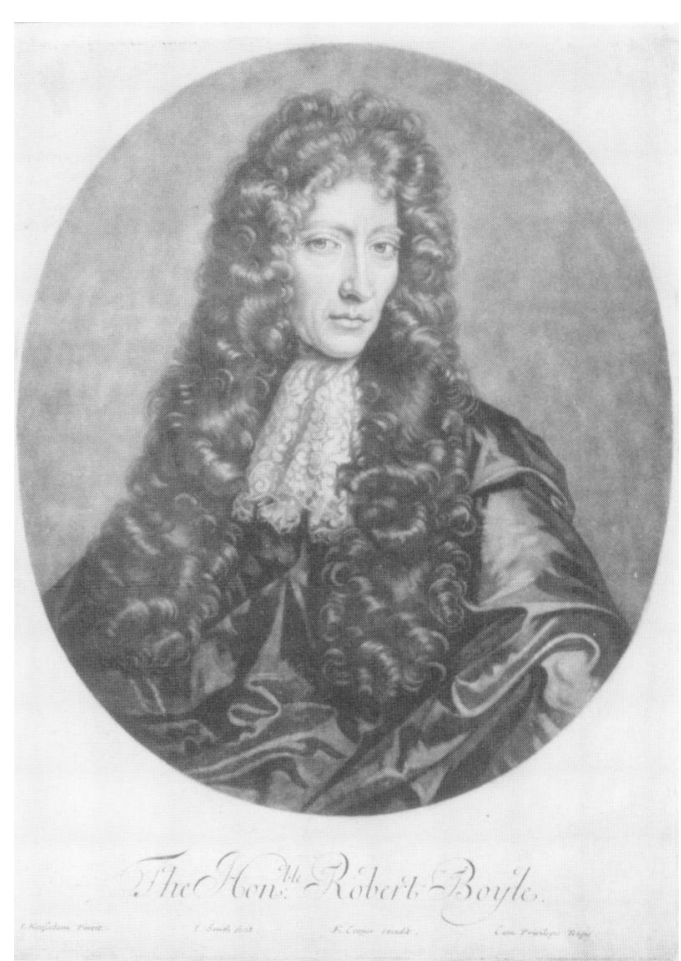

Figure 3 Portrait of Robert Boyle. Courtesy of the Wellcome Institute for the History of Medicine. 
linity, bile, urea, and sugar (the latter was assessed by tasting the urine). ${ }^{8}$

Several instruments, such as the polaroscope, colorimeter and spectroscope, had also been invented by the year 1860, and information on all of these were included in the volume by Neubauer and Vogel. Even these tests, however, are a far cry from the much more advanced tests and techniques based on modern technology available today, either routinely or experimentally. To quote but a few examples there are analyses for steroids, amines, porphyrins, and organic acids. There are also more recently developed molecular biological techniques, one specific example being is the reverse transcription polymerase chain reaction (RT-PCR) which is performed on urinary sediment and is used for the diagnosis of uroepithelial malignancies. ${ }^{9}$
1 Strauss MB (ed). Familiar medical quotations. Boston: Little Brown, 1968.

2 Lines JG. A chronicle of the development of clinical chemistry. IFCC Newsletter 1977;18:3-9.

3 Rosner F, Munter S. Moses Maimonides' aphorisms C regarding analysis of urine. Ann Intern Med 1969;71:217- $\bigcirc$ 20.

4 Foster WD. Chemical pathology. In: $A$ short history of clinical $\frac{J}{0}$ pathology. London: E and S Livingstone Ltd, 1961:34-51.

5 Bush RB. Urine is an harlot, or a liar. $¥ A M A$ 1969;208:131- 을 4.

6 Keele KD. The quest for significant physical signs. In: The evolution of clinical methods in medicine. Part II. London: Pitman Medical Publishing, 1961:21-49.

7 Keele KD. The impact of science on clinical methods: the 등 basic sciences. In: The evolution of clinical methods in medi- $\overline{\bar{n}}$ cine. Part III. London: Pitman Medical Publishing,
1961:50-74.

8 Brock WH. Matter and medicine. In: From protyle to proton: William Prout and the nature of matter, 1785-1985. Bristol, Boston: Adam Hilger Ltd, 1985:12-33.

9 Matsumura Y, Hanbury D, Smith J, Tarin D. Non-invasive detection of malignancy by identification of unusual CD44 gene activity in exfoliated cancer cells. BMF 1994;308:619-24. 